The hypocretin/orexin system: implications for drug reward and relapse

Ainhoa Plaza-Zabala, Rafael Maldonado and Fernando Berrendero ${ }^{\#}$

Laboratory of Neuropharmacology, Department of Experimental and Health Sciences, University Pompeu Fabra, PRBB, C/ Doctor Aiguader 88, 08003 Barcelona, Spain

\# Corresponding author: Fernando Berrendero, Phone: +34-93-3160890; Fax: + 34-93-

3160901; E-mail: fernando.berrendero@upf.edu 


\begin{abstract}
Hypocretins (also known as orexins) are hypothalamic neuropeptides involved in the regulation of sleep/wake states and feeding behavior. Recent studies have also demonstrated an important role for the hypocretin/orexin system in the addictive properties of drugs of abuse, consistent with the reciprocal innervations between hypocretin neurons and brain areas involved in reward processing. This system participates in the primary reinforcing effects of opioids, nicotine and alcohol. Hypocretins are also involved in the neurobiological mechanisms underlying relapse to drug-seeking behavior induced by drug-related environmental stimuli and stress, as mainly described in the case of psychostimulants. Based on these preclinical studies, the use of selective ligands targeting hypocretin receptors could represent a new therapeutical strategy for the treatment of substance abuse disorders. In this review, we discuss and update the current knowledge about the participation of the hypocretin system in drug addiction and the possible neurobiological mechanisms involved in these processes regulated by hypocretin transmission.
\end{abstract}

Key words: hypocretin, addiction, reward, self-administration, relapse, stress 


\section{The Hypocretin/Orexin System}

Co-discovered in 1998 [1, 2], hypocretins (also known as orexins) have long been described as exclusive central nervous system (CNS) peptides. However, amassing evidence indicates the existence of hypocretins and their receptors in the periphery [3], which suggests the presence of additional sources for these peptides. Multiple aspects of hypocretins functions still remain unknown and this article has been focused on the role of central hypocretin signaling in drug-reward and addiction.

Hypocretin-1/Orexin-A and hypocretin-2/orexin-B are 33- and 28- amino acid (AA) residue peptides proteolytically cleaved from a common precursor peptide of 130 AA, preprohypocretin/preproorexin [1, 2]. Hypocretins are present from vertebrate fish to mammals $[4,5]$ and mammalian hypocretin peptides are highly conserved in all the species [6], suggesting a critical role in evolution. Human hypocretin-1 and -2 share $46 \%$ sequence homology and hypocretin- 1 is identical in a series of mammalian species, while hypocretin- 2 differs in 1 or 2 AA from human to other mammalians. The $\mathrm{C}$ terminal sequence of both hypocretin peptides is highly conserved and posttranslationally amidated [2]. However, only the N-terminal sequence of hypocretin-1 is cyclized into a pyroglutamyl residue [2]. Hypocretin-1 is also post-translationally stabilized by two intrachain disulfide bonds whereas hypocretin-2 remains a linear peptide [2]. As other neuromodulatory peptides, neuronal hypocretins are stored in secretory vesicles, accumulated at axon terminals and released in a $\mathrm{Ca}^{2+}$ sensitive manner [1]. Two closely related G-protein coupled receptors that respond to hypocretins have been cloned, hypocretin or orexin receptor-1 (Hcrtr-1/OxR1) and hypocretin or orexin receptor-2 (Hcrtr-2/OxR2) [2]. Human Hcrtr-1 (425 AA) and Hcrtr-2 (444 AA) share $64 \%$ sequence identity [2, 6] and Hcrtr-1 binds with 100-1000 higher affinity to hypocretin-1 than hypocretin-2. In contrast, Hcrtr-2 binds both hypocretins with similar 
affinity $[2,7,8]$. As the C-terminal region of both peptides is highly conserved, it has been proposed that the $\mathrm{N}$-terminal sequence is responsible for the higher preference of Hcrtr-1 for hypocretin-1 [9].

The cellular signals triggered upon hypocretin receptor activation have been largely investigated but remain still to be elucidated. In native-receptor-expressing neurons, stimulation of both hypocretin receptors leads to a prominent increase in intracellular $\mathrm{Ca}^{2+}$ concentrations through the activation of $\mathrm{Gq}$ proteins followed by phospholipase $\mathrm{C}$ and subsequent protein kinase C (PKC) stimulation [10-14]. The activation of this kinase phosphorylates and modulates effector ion channels leading to $\mathrm{Ca}^{2+}$ entrance, among other effects $[6,15]$. Hcrtr-1 is thought to signal only through Gq proteins in neurons, although a recent report showed that Hcrtr-1 stimulation lead to cyclic AMP production in primary cultures of rat astrocytes [16], suggesting the existence of Gscoupled signal transduction through Hcrtr- 1 . The $\mathrm{Ca}^{2+}$ elevation induced by hypocretin receptor activation explains the commonly reported neuroexcitatory nature of hypocretin peptides on the brain [1]. Thus, the most common response to hypocretins is an increase in action potential frequency achieved by pre- and post-synaptic effects. Hypocretin regulation of pre-synaptic glutamate- and GABA-releasing neurons has been identified. Thus, PKC at pre-synaptic terminals phosphorylates and activates presynaptic $\mathrm{Ca}^{2+}$ channels facilitating neurotransmitter release [10, 17, 18]. Additionally, post-synaptic activated PKC phosphorylates and regulates the function of diverse effector ion channels $[6,15]$, finally leading to depolarization. In contrast, few reports relate hypocretins to synaptic inhibition [19-22]. Although the molecular mechanisms regarding hypocretin-induced synaptic inhibition have not been clarified, Hcrtr-2 has been shown to couple to inhibitory Gi proteins that prevent cyclic AMP formation [23]. 
In the CNS, hypocretin expression is restricted to a few thousand neurons in some particular regions of the hypothalamus: the perifornical area (PFA), the dorsomedial hypothalamus (DMH) and the dorsal and lateral hypothalamus (LH) [1, 2, 24]. Although hypocretin-containing neurons represent a relatively small number of cells, their projections are widely distributed throughout the brain (Figure 1) [24]. Hypocretin fibers are spread along the entire hypothalamus, which suggests an important role in energy homeostasis and other autonomic functions. The largest amount of extrahypothalamic projections are found in brainstem nuclei, such as the raphe nuclei, the reticular formation and especially the locus coeruleus [24], a brain nucleus involved in the regulation of behavioral arousal. Hypocretin neurons also send significant efferent projections to structures related with drug-seeking and addiction, such as the paraventricular nucleus of the thalamus, the septal nuclei, the bed nucleus of the stria terminalis, the anterior and central amygdaloid nuclei and the ventral tegmental area (VTA). Disperse axons are also found throughout the cortex and the medial part of the nucleus accumbens (NAcc) shell [24, 25]. Both hypocretin receptor subtypes are found in similar brain areas than hypocretin fibers and the distribution of both receptors is partially overlapping, although some particular areas essentially express one receptor subtype. Thus, the prefrontal cortex predominantly expresses Hcrtr-1 and the NAcc mainly Hcrtr-2 [26], suggesting that each receptor could regulate distinct functions in the reward circuit.

The widespread extension of the hypocretin system in the CNS is in agreement with the variety of physiological functions of hypocretin peptides, that includes energy homeostasis, behavioral arousal, sleep/wake cycles, and reward-seeking and addiction, amongst others [27]. Recent evidence also points to a role for the hypocretin system in other CNS disorders, such as Alzheirmer's disease [28] and panic anxiety disorders 
[29]. Initially, hypocretins emerged as regulators of feeding behavior and the alternative name "orexin" was devised upon the observation that intra-ventricular infusion of hypocretins increased food-intake in rats [2]. Nevertheless, this response is now considered to be an indirect effect of the wake-promoting effects of hypocretins and not directly related to the regulation of satiety states and energy balance $[30,31]$. On the other hand, the role of hypocretin signaling in the promotion of wakefulness/arousal is unquestionable [32] and narcolepsy is the clearest evidence for aberrant hypocretin transmission in pathophysiological conditions. Genetic ablation of preprohypocretin or Hcrtr-2 gene in rodents results in a phenotype similar to human narcolepsy with cataplexy $[33,34]$. In agreement, dogs with a mutation in the Hcrtr-2 gene also display the same phenotype [35]. Furthermore, some human narcoleptics have undetectable hypocretin levels in the cerebrospinal fluid [36] and lack hypocretin-producing neurons in the hypothalamus [37]. Thus, Hcrtr-2 agonists might be useful for narcoleptic patients whereas hypocretin receptor antagonists might serve for the treatment of insomnia [38].

Arousal and wakefulness promoting stimuli are often associated with stress and anxiety. Indeed, hypocretin-containing neurons are sensitive to corticotrophin-releasing factor (CRF) neurons and can also regulate the activity of these cells [39], suggesting a role for hypocretins in stress-related behaviors [40]. Stress is a key element of the negative emotional states associated to drug withdrawal and represents a crucial factor for drug-seeking behavior [41]. Hypocretin signaling could contribute to drug-seeking in part by modulation of stress responses. Thus, intra-ventricular and intra-VTA infusions of hypocretin-1 decreases the activity of the brain reward system [42, 43], similarly to CRF [44] and drug withdrawal [45, 46]. However, in contrast to the previous data, intra-VTA infusion of hypocretin-1 and -2 increased dopamine levels in 
the NAcc [47, 48] and the prefrontal cortex [49] of rats, indicating a role for hypocretins in the regulation of the dopaminergic mesocorticolimbic system and reward-learning. Moreover, hypocretin-1 is critical for the induction of synaptic plasticity in the VTA [50], which accounts for relapse after long periods of abstinence. In agreement with these findings, several behavioral studies using models of drug reward and relapse support the involvement of hypocretin transmission in the addictive properties of drugs of abuse.

\section{Animal models of drug reward and relapse}

Several predictive animal models are available to study responses related to the rewarding effects produced by the different drugs of abuse. These procedures include the intracranial electric self-stimulation paradigms that evaluate the effects of the drug in the brain reward circuits, the self-administration methods that directly measure the reinforcing properties and the conditioned place preference that assesses conditioned responses related to the rewarding effects. These experimental models have been useful to define the neurobiological substrate involved in the rewarding effects of drugs of abuse that are crucial for the addictive process. However, one of the most important clinical concerns for the treatment of drug addicts is the very high rate of relapse even after long periods of drug abstinence [51]. Several behavioral models have also been validated in experimental animals to mimic some aspects of drug relapse in human addicts. The vast majority of animal studies on drug relapse are based on reinstatement models $[52,53,54]$. Reinstatement refers to the recovery of a learned response that occurs when a subject is exposed to some particular stimuli after extinction of such a response [55]. 
The neurobiological mechanisms underlying the different behavioural responses evaluated in these animal models of reward and reinstatement have been clarified by using several neurochemical and electrophysiological techniques. Electrophysiological techniques that determine the firing rates of neurons have been widely used to investigate the changes in the activity of intrinsic and synaptic currents of neurons involved in the reward circuits [56]. These electrophysiological recordings have been performed in vivo in whole animals as well as ex vivo in isolated brain slice preparations [57]. Ex vivo studies in brain slices are useful to differentiate the intrinsic responses of the neurons from those that are dependent on the activity of afferent neuronal projections. In vivo electrophysiological studies have identified the specific firing responses of neurons involved in reward processes, such as dopaminergic neurons, to several rewarding stimuli including drugs of abuse, and have provided interesting correlates with the responses evaluated in the different behavioural models [56].

Among the different neurochemical procedures, the use of in vivo microdialysis techniques has provided crucial advances in the knowledge of the neurobiological substrate of the reward circuits [58]. In vivo microdialysis techniques in freely moving rodents allow the measurement of the extracellular levels of neurotransmitters in discrete areas of the central nervous system, which represents a direct reflection of the balance between synaptic release and uptake/clearance of these neurotransmitters. The use of this technique in line with behavioural studies has allowed to identify the neurochemical changes that are associated to particular behavioural tasks, such as the enhancement in the extracellular levels of dopamine in the reward pathways after the administration of all the prototypical drugs of abuse [59]. 
One of the behavioural paradigms widely used to study the effects of drugs of abuse on the activity of the reward circuits is the intracranial electric self-stimulation procedure [60]. In this paradigm, animals are trained to maintain an operant behavior to obtain an electric pulse through an electrode placed in a reward-related brain site, most frequently the lateral hypothalamic area. The threshold of the minimal current needed to promote intracranial electric self-stimulation is usually estimated. A drug that stimulates the reward circuit will decrease this threshold, which would be related to its rewarding properties, whereas a drug or a state of withdrawal producing aversive effects will enhance the minimal current required to maintain the self-stimulation [61]. Intracranial electric self-stimulation paradigms are useful to investigate the rewarding effects of drugs of abuse, but have not been used as animal models of reinstatement of drugseeking behavior.

The most reliable and predictive animal models of reinstatement involve operant self-administration procedures based on operant conditioning paradigms [53]. Selfadministration models mimic drug-taking behavior in humans and are widely used to directly evaluate the primary reinforcing properties of drugs. These operant procedures are considered by most researchers to be reliable models of drug consumption in humans with a high predictive value [60]. In these models, animals are trained to respond in order to obtain a drug intravenous infusion or an oral solution in the case of alcohol, typically by pressing a lever or nose poking in a hole. The operant chambers are equipped with these manipulandi that transmit the operant response as well as devices that deliver the drug (reinforcer). The response in the active manipulandum is linked to the delivery of the drug, while the response in the inactive manipulandum results in the delivery of the drug vehicle or lacks any programmed consequence. The fixed ratio and progressive ratio schedule reinforcement programs are commonly used. 
Under a fixed ratio schedule, the drug is delivered each time a pre-selected number of responses is completed. Under the progressive ratio schedule, the response requirement to deliver the drug escalates according to an arithmetic progression. The common index of performance evaluated in this schedule is the breaking point defined as the highest number of responses that the animal accomplishes to obtain a single infusion of drug, which provides information about its motivation for the drug. The analysis of this instrumental response provides valuable information about different behavioral aspects of drug consumption. After acquisition of the operant task, the behavioral responding can be extinguished by exposing the animals to an additional training where the reward is not longer available. The operant behavior to seek the drug can be then reinstated by using different stimuli.

Several researchers have developed drug reinstatement procedures in rats and mice using the place conditioning paradigm [62]. In the place conditioned paradigms, the subjective effects of the drug are repeatedly paired to a previously neutral spatial environmental stimulus. Through this repeated association process, the environment acts as a conditioned stimulus. The animal will then prefer (conditioned place preference) or avoid (conditioned place aversion) this conditioned stimulus, depending on the rewarding or aversive effects produced by the administration of the drug. Although a conditioned approach/avoidance towards specific stimuli can also occur in humans as a result of drug consumption [63], the place conditioning paradigms are not primarily intended to model any particular feature of human behavior. These paradigms mainly represent an indirect assessment of the rewarding or aversive effects of a drug by measuring the response of the animal towards the conditioned stimulus. Two different phases (acquisition and expression) of the place conditioning that have different psychological implications are evaluated in this paradigm. Indeed, acquisition seems to 
be related to reward and learning whereas expression would be more related to incentive motivation, memory recall or sign-tracking. However, some of the effects obtained in the place conditioning paradigms may reflect state-dependent learning due to discriminative stimuli properties of the test drug rather than rewarding effects [64], which represents a limitation for the interpretation of the reinstatement models based on these paradigms.

It has been postulated that the reinstatement of drug seeking behavior could be related to the appearance of a behavioral sensitization to the motor stimulant responses induced by some drugs of abuse [65]. Thus, behavioral sensitization and reinstatement of drug seeking behavior involve some overlapping circuitry, and neurotransmitter and receptor systems [65]. However, the relationships between these two distinct behavioral responses still remain controversial.

The rodent reinstatement models based on the operant drug self-administration procedures have been widely validated in rats. Nevertheless, the genetically modified laboratory animals available to date have mainly been inbred mouse strains. Therefore, it is crucial to extend these high predictive drug self-administration reinstatement models in rats to mice. Nowadays, reliable mouse models of relapse based on wellestablished extinction-reinstatement procedures in rats have been validated. Thus, new mouse models of reinstatement of seeking behaviour to cocaine [66], methamphetamine [67], MDMA [68], alcohol [69], nicotine [70], morphine (unpublished results from our laboratory) and even palatable food [71] are now available. These new mouse operant models of reinstatement represent excellent tools for the advance in the understanding of the neurobiological mechanisms underlying drug relapse. 


\section{Stimuli triggering drug relapse}

One of the main strength of the drug self-administration reinstatement models in rodents is their high predictive validity. Predictive validity in an animal behavioral model refers to the extent to which the behavior induced in the experimental paradigm predicts human behavior induced by a similar event, and it is essential for the translational value of the animal model [72]. Indeed, craving and relapse to drug intake are mainly provoked in human addicts by the re-exposure to the drug of abuse [73], drug-associated cues [74] or stressful situations [75], that are exactly the same stimuli used to reinstate drug-seeking behavior in the rodent drug self-administration models.

The re-exposure to the drug is one of the most well-known stimuli triggering the relapse of drug-seeking in human addicts [73]. In agreement, drug priming administration has been widely used as an effective stimulus to reinstate extinguished responding of drug-seeking in multiple animal models. Drug priming has been the first stimulus used to validate experimental models of renew extinguished responding of drug-seeking in animals [76], and has been used over three decades for these purposes [64]. In these animal models, the drug is usually administered non-contingently in order to promote the reinstatement of the operant behavior.

The exposure to environmental cues that were previously associated with drug taking is another widely known factor that triggers drug relapse in humans [74]. The reinstatement of drug-seeking behavior induced by conditioned cues associated to drug self-administration has been used to model this situation in animals [77]. Different cues have been employed to reinstate extinguished responding of drug-seeking. Thus, discrete cues (typically lights or tones) that are associated with each reward delivery during the training period have been widely used to reinstate drug-seeking after extinction of the operant behavior [77]. Another procedure consists in the use of 
discriminative cues. For this purpose, rodents are trained to self-administer a drug in the presence of specific discriminative stimuli and saline in the presence of a different set of stimuli. Operant behavior is then extinguished in the absence of the discriminative stimuli and is reinstated by the re-exposure of these stimuli [78]. Contextual reinstatement stimuli have also been applied. Under these situations, rodents are first trained to self-administer the drug in a context with specific cues that reveals the availability of the reinforcer and the operant behavior is extinguished in a different context that contains other specific cues. The re-exposure to the animal to the drugpaired context reinstates drug-seeking behavior [79].

In humans, negative affective states such as anger, stress, anxiety or depression can trigger relapse to drug taking $[75,80]$. Stress-induced reinstatement of extinguished responding of drug-seeking has been widely used to model in animals this human situation [53]. The most successfully employed stressors in these animal reinstatement paradigms are the exposure to intermittent foot-shocks $[66,81]$ and the administration of pharmacological agents inducing stress $[82,83]$.

The rodent reinstatement models using these three different kinds of stimuli were first validated in rats and are now also available in mice with a similar predictive validity $[66-68,70]$.

\section{Role of the hypocretin/orexin system in psychostimulant rewarding properties and} relapse

The involvement of the hypocretin system in the rewarding properties of psychostimulants has not been still fully clarified (Table 1). Amphetamine-sensitized rats showed increased Fos levels in hypocretin neurons of the LH [84, 85]. Additionally, the Hcrtr-1 antagonist SB334867 blocked the effects of amphetamine on extracellular 
dopamine levels in the NAcc shell and the expression of amphetamine-induced locomotor sensitization [86]. Rats conditioned to cocaine in a place preference paradigm also showed increased Fos expression in LH hypocretin cells [87], even though the administration of SB334867 did not modify the expression of cocaine place preference [88]. Interestingly, mice receiving systemic and intra-VTA injections of the Hcrtr-1 antagonist SB334867 as well as mice lacking the preprohypocretin gene showed attenuated basal and cocaine-enhanced dopamine extracellular levels in the NAcc [48]. Consistent with this, intra-VTA infusion of hypocretin-1 increased basal dopamine extracellular levels in the NAcc, and the effects of cocaine on evoked dopamine release and uptake inhibition in this brain structure [89]. These biochemical results suggest that hypocretin signaling critically modulates cocaine effects on mesolimbic dopamine transmission.

In spite of these findings, contradictory results have been obtained using the operant cocaine self-administration paradigm. So far, self-administration studies have not yet demonstrated the participation of hypocretins in the primary reinforcing properties of cocaine when using a fixed-ratio 1 schedule of reinforcement [42, 48, 89, 90]. Nevertheless, when access to cocaine self-administration is limited or under conditions that require a higher effort to obtain a cocaine infusion, an involvement of the hypocretin system in cocaine reinforcement has been revealed. Thus, SB334867 reduced responding for cocaine when using a 24-hour access self-administration procedure in which the number of injections that the animal can receive each hour is limited (discrete trial procedure) [48]. On the contrary, an intra-ventricular infusion of hypocretin-1 increased lever-pressing in the same experimental paradigm [89]. The systemic or intra-VTA administration of SB334867 significantly reduced the breaking point achieved on a progressive ratio schedule of reinforcement in rats self- 
administering cocaine $[48,91]$. Similarly, this Hcrtr-1 antagonist decreased the rate of responding for cocaine by using a self-administration paradigm in which the demand of responding progressively increases to maintain blood levels of cocaine (threshold selfadministration paradigm) [48]. Conversely, intra-VTA infusions of hypocretin-1 increased the motivation to self-administer cocaine on a progressive ratio schedule [89], suggesting that the enhancement of hypocretin transmission in this particular brain structure increases the reinforcing efficacy and the motivation to obtain cocaine.

The participation of the hypocretin system in the reinstatement of cocaine-seeking induced by the presentation of different stimuli has been extensively investigated. An intra-ventricular infusion of hypocretin-1 induced reinstatement of a previously extinguished cocaine-seeking behavior [42]. This effect was attenuated by the pretreatment with the $\alpha_{2}$ agonist clonidine that decreases noradrenergic activity and the $\mathrm{CRF}_{1} / \mathrm{CRF}_{2}$ antagonist $\mathrm{D}-\mathrm{Ph} \mathrm{CRF}_{12-41}$, suggesting a role for noradrenaline and $\mathrm{CRF}$ on hypocretin-1-induced reinstatement [42]. In agreement, the systemic injection of a high dose of SB334867 attenuated foot-shock stress-induced reinstatement of cocaineseeking [42]. These results suggest that hypocretin and CRF systems interact to regulate cocaine-seeking behavior. Intra-VTA infusion of hypocretin-1, but not hypocretin-2, also induced reinstatement of cocaine-seeking [92]. Nevertheless, in contrast to the data described above, this behavioral response was not blocked by the intra-VTA perfusion of the antagonist alpha-helical $\mathrm{CRF}_{9-41}$ [92]. Furthermore, foot-shock stress-induced reinstatement of cocaine-seeking was not attenuated by the intra-VTA administration of the Hcrtr-1 antagonist SB408124 [92]. Therefore, these findings suggest that, at least at the level of the VTA, hypocretin and CRF modulate cocaine-seeking behavior by independent mechanisms. 
More recently, Hcrtr-1 signaling was found to be necessary for cue- and contextinduced cocaine-seeking [90, 93, 94] but not for cocaine-primed reinstatement [94]. Cocaine-seeking elicited by drug-paired cues was not blocked by the pretreatment with an Hcrtr-2 antagonist [90], indicating a functional difference between both hypocretin receptors in the regulation of this effect. VTA hypocretin signaling, unlike what occurs in stress-induced reinstatement, has been shown to play a role in cue-elicited cocaine relapse. Thus, the intra-VTA infusion of SB334867 dose-dependently attenuated cueinduced cocaine-seeking behavior [95]. This effect was not observed when infusing the Hcrtr-1 antagonist into the paraventricular thalamus [95].

Remarkably, cocaine-induced glutamatergic synaptic plasticity in VTA dopamine neurons is also dependent on hypocretin inputs [50]. Pretreatment with SB334867 blocked the glutamate-dependent long term potentiation induced by cocaine in dopamine neurons of the VTA. Moreover, systemic or intra-VTA administration of SB334867 blocked the acquisition of cocaine-induced locomotor sensitization [50]. These data provided the first link between hypocretin signaling and glutamatergic synaptic plasticity in cocaine behavioral responses related to addiction. This hypocretindependent cocaine-induced synaptic plasticity in the VTA could be involved in facilitating the transformation of neutral environmental stimuli into salient rewardpredictive cues [96], which could explain the role of Hcrtr-1 in cue- and contextinduced reinstatement of cocaine-seeking.

\section{Role of the hypocretin/orexin system in morphine rewarding properties and relapse}

Several studies suggest that hypocretin transmission plays an important role in the rewarding properties of opioids (Table 2). Rats that exhibited a preference for an 
environment previously associated to morphine in a place conditioning paradigm showed an activation of hypocretin neurons, as revealed by Fos immunostaining [87]. Moreover, significant positive correlations were found between the percentages of activated hypocretin neurons in the LH and the morphine preference scores [87]. Bilateral excitotoxic lesions of hypocretin-enriched area of the LH completely blocked the acquisition of morphine conditioned place preference [97]. Pharmacological studies using the selective Hcrtr-1 antagonist SB334878 confirmed the involvement of this receptor in the rewarding properties of morphine. Thus, systemic $[87,88]$ or intra-VTA [47] administration of the Hcrtr-1 antagonist SB334867 reduces morphine-induced place preference in rats. However, conflicting results have been found in mice lacking the preprohypocretin gene since a suppression [47] or similar [88] morphine place preference have been reported in these mutant animals. Similar discrepancies were reported in the hyperlocomotor effects of morphine in preprohypocretin knockout mice $[47,88]$. In spite of these controversial findings, behavioral studies using operant selfadministration procedures to evaluate the role of hypocretins in the reinforcing properties of opioids are still missing. The mechanisms underlying the effects of the hypocretin system on morphine rewarding properties are related to a modulatory response on morphine-induced activation of the mesolimbic dopaminergic pathway. Thus, in vivo microdialysis studies revealed that the enhancement of the extracellular levels of dopamine in the NAcc induced by morphine was significantly decreased by deletion of the preprohypocretin gene [47].

The hypocretin system also participates in the behavioral and biochemical manifestations of the morphine withdrawal syndrome. Somatic signs of morphine withdrawal were attenuated in preprohypocretin knockout mice [98] and in mice pretreated with SB334867 before naloxone-precipitated morphine withdrawal [99]. 
Recently, a specific participation of Hcrtr-1 located within the locus coeruleus in morphine physical dependence has been reported [100]. Consistent with these behavioral data, naltrexone or naloxone-precipitated morphine withdrawal leads to the induction of Fos expression in hypocretin cells [98, 99], and spontaneous morphine withdrawal increases hypocretin mRNA levels in the LH [101].

Few studies have examined the implication of the hypocretinergic system in animal models of opioid relapse. Chemical activation of LH hypocretin neurons reinstated an extinguished morphine place preference [87], which was completely blocked by prior systemic administration of the Hcrtr-1 antagonist SB334867 [87]. In addition, the injection of hypocretin-1 in the VTA, but not in areas surrounding this brain structure, caused a significant reinstatement of the previously extinguished morphine place preference [87], suggesting a role for hypocretins acting on the VTA in the mechanisms driving to relapse of morphine-seeking. Behavioral studies using operant selfadministration paradigms would be useful to confirm the involvement of hypocretins in this behavioral response related to morphine addictive properties.

\section{Role of the hypocretin/orexin system in nicotine rewarding properties and relapse}

Nicotine addiction is a complex neurochemical process in which many neurotransmitters are involved [102, 58] and growing evidence suggests that hypocretins play also a crucial role in nicotine addictive effects [103] (Table 3). Acute nicotine injections as well as mecamylamine-precipitated nicotine withdrawal increased Fos expression in hypocretin neurons of the LH [104-106]. Additionally, acute nicotineinduced activation of the paraventricular nucleus of the hypothalamus was dependent on hypocretin transmission [105]. On the other hand, intravenous nicotine selfadministration modified Hcrtr-1 mRNA levels in the arcuate nucleus and the rostral 
lateral areas of the hypothalamus in rats [107]. In agreement, non-contingent chronic nicotine administration also regulated preprohypocretin and hypocretin receptor mRNA levels in the rat hypothalamus [108]. At the behavioral level, pretreatment with the Hcrtr-1 antagonist SB334867 or the Hcrtr-1/-2 antagonist almorexant decreased intravenous nicotine self-administration in rats under a fixed-ratio 5 schedule of reinforcement [107, 109]. In addition, SB334867 decreased the number of nicotine rewards earned under a progressive ratio schedule [109] suggesting that hypocretins acting on Hcrtr-1 regulate nicotine reinforcement and the motivation to seek the drug. Interestingly, stroke-associated damage to the insular cortex in human smokers resulted in spontaneous cessation of the smoking habit and a low urge to smoke [110]. Based on these findings, it was hypothesized that hypocretin transmission in the insular cortex might have a role in nicotine reinforcement. Notably, intra-insular infusion of the Hcrtr1 antagonist SB334867 decreased nicotine intake in rats [109]. The mechanism by which hypocretins modulate nicotine rewarding and motivational properties could involve the regulation of the stimulatory effects of nicotine in brain reward systems. Indeed, pretreatment with SB334867 blocked the nicotine-induced lowering of the intracranial self-stimulation thresholds in rats [109]. Consistent with rodent studies, recent evidence in human smokers also points to a role of hypocretin transmission in tobacco addiction. Thus, a negative correlation between hypocretin plasma concentration and nicotine craving has been shown [111].

The hypocretin system seems also to participate in nicotine-seeking behaviors. Indeed, hypocretin-1, through Hcrtr-1 activation, reinstated a previously extinguished nicotine-seeking behavior in mice [105]. The $\mathrm{CRF}_{1}$ receptor antagonist antalarmin did not block the effects of hypocretin-1 on reinstatement, whereas the Hcrtr-1 antagonist SB334867 did not modify the CRF-dependent stress-induced reinstatement of nicotine- 
seeking [105]. These results suggest that the mechanism by which hypocretin-1 induces reinstatement of nicotine-seeking is independent of the CRF system. Additional research will be needed to elucidate the potential participation of hypocretins in the other two modalities to reinstate nicotine-seeking behavior (nicotine-associated cues and re-exposure to nicotine). Impaired attention is an established cognitive symptom of nicotine withdrawal that could contribute to smoking relapse. Interestingly, hypocretins could participate in the attention enhancing effects of nicotine [112, 113], which suggests that the hypocretin system may contribute to nicotine addiction not only by the modulation of the rewarding effects but also through the modification of nicotine cognitive effects.

On the other hand, a selective involvement of Hcrtr-1 in the expression of nicotine withdrawal has been recently reported [106]. Pretreatment with SB334867, but not with the specific Hcrtr-2 antagonist TCSOX229, attenuated the somatic signs of nicotine withdrawal in mice. In addition, a crucial role for the hypothalamic paraventricular nucleus in the modulation of this effect was revealed. Thus, the increase in Fos expression that occurred in the paraventricular nucleus of the hypothalamus during nicotine withdrawal was dependent on hypocretin transmission and local infusion of the Hcrtr-1 antagonist into this brain area attenuated the somatic manifestations of withdrawal [106].

\section{Role of the hypocretin/orexin system in alcohol rewarding properties and relapse}

Hypocretin transmission seems to play an important role in the addictive properties of alcohol [114], although conflicting results are reported in the literature (Table 4). The pretreatment with SB334867 decreased operant responding for alcohol under a fixed ratio 3 schedule in alcohol preferring rats [115], while no effect of this Hcrtr-1 
antagonist was observed on water responding. Subsequent studies confirmed the involvement of Hcrtr-1 in the reinforcing effects of alcohol. Thus, SB334867 also reduced alcohol, but not sucrose, self-administration in Long-Evans rats [116]. The same Hcrtr-1 antagonist reduced ethanol preference on a two-bottle free-choice paradigm in rats [117]. In addition, a recent report has revealed a role for Hcrtr-1 in the motivation to self-administer alcohol since SB334867 pretreatment reduced the breaking point for alcohol, but not for sucrose, on a progressive ratio schedule of reinforcement [118]. Consistent with these behavioral data, the infusion of hypocretin-1 in the hypothalamic paraventricular nucleus or the LH, but not into the NAcc, stimulated voluntary ethanol intake without significantly altering food and water intake [119]. Chronic ethanol consumption in alcohol preferring rats increased the area of expression of mRNA encoding preprohypocretin within the LH [115], although a reduction of hypocretin expression in the perifornical lateral hypothalamus has also been observed following chronic ethanol intake in rats [120]. Interestingly, a recent report has revealed a novel role for Hcrtr-2 in the reinforcing effects of ethanol. Thus, the specific Hcrtr-2 antagonist JNJ-10397049 dose-dependently reduced ethanol selfadministration without changing saccharin self-administration in rats [121]. In addition, the same antagonist attenuated the acquisition and expression of ethanol-induced place preference. Surprisingly, the Hcrtr-1 antagonist SB408124 was ineffective in reducing the reinforcing effects of ethanol in this study [121]. In agreement, blockade of Hcrtr-1 by SB334867 did not affect the acquisition and expression of ethanol-induced conditioned place preference in mice [122], suggesting that Hcrtr-1 does not influence ethanol's primary or conditioned rewarding effects. Differences in experimental procedures and animal species could explain the discrepancies about the role of Hcrtr-1 in the ethanol rewarding responses, but additional research will be necessary to fully 
characterize and clarify the role of the hypocretin system in these motivational properties of ethanol.

Alcohol relapse induced by associated environmental stimuli is also modulated by the hypocretin system. Thus, SB334867 prevented cue-induced reinstatement of alcohol-seeking in alcohol preferring rats [115]. An attenuation of alcohol relapse by this Hcrtr-1 antagonist was also observed in the same animal species after protracted alcohol abstinence [123]. Moreover, context- [124] and cue-induced alcohol-seeking [125] was found to activate hypocretin-containing neurons in the hypothalamus as revealed by Fos protein expression studies. Neuropeptide S, an endogenous brain peptide which promotes arousal and anxiolytic-like responses [126], seems to be involved in the modulation that hypocretins exert on ethanol-seeking behavior. Thus, the activation of neuropeptide $\mathrm{S}$ receptors in the $\mathrm{LH}$ intensified relapse to ethanolseeking elicited by environmental conditioning factors [127]. This increase of alcohol seeking induced by neuropeptide $S$ required also the activation of the hypocretin system [127]. Moreover, Hcrtr-1 signaling is involved in stress-induced reinstatement of alcohol-seeking behavior. Accordingly, SB334867 blocked the relapse to ethanolseeking induced by yohimbine, an $\alpha_{2}$ noradrenergic antagonist that provokes a stresslike response in both humans and laboratory animals [116]. Consistent with the preclinical data, recent studies in humans suggest an involvement of hypocretins in the affective dysregulation that appears in alcohol dependent patients during alcohol withdrawal and craving $[128,129]$. 


\section{Potential mechanisms involved in the modulation of the addictive properties of drugs of abuse by hypocretins}

The data described above suggest that the hypocretin system plays a crucial role in the addictive properties of several major drugs of abuse, including psychostimulants, opioids, nicotine and alcohol. However, hypocretin transmission regulates the primary reinforcing effects of opioids, nicotine and alcohol, but not those of psychostimulants. The differential participation of the hypocretin system in the reinforcing properties of psychostimulants could be explained by the different action upon the mesolimbic system. Although all drugs of abuse increase dopamine extracellular levels in the NAcc, opioids, nicotine and alcohol increase dopaminergic cell firing in the VTA whereas psychostimulants directly inhibit dopamine uptake in the NAcc. These differences suggest that the VTA might be a crucial site of action for hypocretins to mediate the rewarding effects of different drugs of abuse [130]. Therefore, behavioral effects that depend on increased VTA dopaminergic activation (opioid/alcohol/nicotine reinforcement) would be attenuated by Hcrtr-1 antagonists because they may require hypocretin transmission. However, behaviors which are independent of the activation of VTA dopamine cells (primary cocaine reinforcement) could avoid this critical site of action of hypocretins. On the other hand, different hypocretin neuron populations of the hypothalamus seem to be involved in the modulation of the rewarding processes [131]. Thus, LH hypocretin neurons that project to the VTA could be mainly activated by reward-related stimuli [87] while those located in the PFA/DMH may have a more important role in the regulation of arousal and response to stressful situations [99]. Further studies are required to confirm this different physiological role of the diverse hypocretin cell populations. 
Hypocretins also regulate the reinstatement of drug-seeking behaviors induced by drug-associated cues as mainly described for cocaine and alcohol. The VTA seems to be also a critical brain structure of hypocretin action for these effects. Thus, blockade of VTA Hcrtr-1 signaling attenuates cue-induced reinstatement of cocaine-seeking [95]. Notably, cocaine-induced glutamatergic synaptic plasticity in VTA dopamine neurons, which is involved in relapse [132], depends on hypocretin inputs [50]. Consistent with the implication of VTA as a major site of action for hypocretins and its importance shaping the association between drugs and environmental stimuli, electrophysiological studies have shown an increase of the excitability of VTA dopaminergic neurons by the application of these neuropeptides to midbrain slices [133]. Moreover, this brain structure expresses both hypocretin receptor subtypes [26, 47] and receives substantial projections from LH hypocretin neurons [134], although a small proportion makes synaptic contacts within the VTA [135]. The possible participation of VTA hypocretin transmission in cue-induced reinstatement of drug-seeking behavior of other substance of abuse such as alcohol, nicotine and opioids has still not been elucidated.

Hypocretin projections are found throughout the brain and hypocretin receptors are present in multiple brain regions. Accordingly, hypocretin signaling within brain areas distinct from VTA have also been involved in the regulation of the addictive effects of different drugs of abuse. Thus, Hcrtr-1 into the insular cortex is critically involved in the reinforcing properties of nicotine [109]. Moreover, Hcrtr-1 activation into the hypothalamic paraventricular nucleus [106] and the locus coeruleus [100] regulates the somatic signs of nicotine and morphine withdrawal syndromes, respectively. In addition to the VTA, hypocretin transmission in other brain structures has also been suggested to participate in the processes driving to relapse to drug-seeking behavior. Accordingly, the presentation of cues previously associated to ethanol availability activates neurons 
of the thalamic paraventricular nucleus and it has been suggested that this effect is mediated by hypocretin neurons [125]. In addition, although different brain regions could participate in the regulation of stress-induced reinstatement of cocaine-seeking, VTA is not involved in this behavioral response [92].

The distribution of hypocretin receptors in the brain is partially overlapping and sometimes complementary, suggesting that these receptors could regulate different physiological functions. Indeed, the current knowledge of the pharmacology of the hypocretin system points to a role for Hcrtr-1 in drug-taking behaviors while Hcrtr-2 would be mainly involved in the regulation of sleep-wake cycle [27]. However, so far most of the hypocretin-addiction research has focused on elucidating the function of Hcrtr-1. In contrast, very little is known about the possible role of Hcrtr-2 in these processes due to the lack of available selective Hcrtr-2 antagonists. Thus, research in the hypocretin field would largely benefit on the development of new selective antagonists for the different hypocretin receptors. Moreover, the use of very high doses of the Hcrtr1 antagonist SB334867 in some in vivo studies could have induced disruptive behavioral effects and even block both hypocretin receptor subtypes [136]. Therefore, future research using genetically engineered mice for one or both hypocretin receptors will be crucial to clarify the specific contribution of each receptor to the different stages of drug addiction. Additionally, experiments using viral vectors to knockdown or reexpress hypocretin receptors in time and space controlled conditions will also be important to determine the neural circuits underlying hypocretin signaling in drug addiction. 


\section{Conclusions}

The findings reviewed in this article reveal strong evidence for a critical role of hypocretin signaling in drug addiction. The available data suggest that hypocretin transmission not only participates in the primary reinforcing and motivational properties of drugs of abuse but is also involved in the processes that drive relapse to drugseeking. Hence, hypocretin receptor antagonists might represent a new generation of compounds to treat a wide variety of addictive processes (Figure 2). However, important questions regarding the functional role of the hypocretin system remain to be elucidated. Although the importance of VTA as a critical site of hypocretin action is well documented, future studies will be required to identify other specific brain areas underlying hypocretin activity. The precise contribution of the different hypocretin receptors in the regulation of behaviors associated with addiction needs to be clarified. Several studies have evaluated the interaction between cannabinoids and hypocretins in some physiological responses such as the regulation of feeding [137,138] and nociception [139]. However, the possible role of the hypocretin system in the addictive properties of cannabis, which is one of the most commonly used illicit drugs, remains to be demonstrated. Finally, the improvement of our understanding of the signaling cascades activated by the stimulation of hypocretin receptors will be crucial for the development of more specific drugs with different efficacy profiles. 


\section{Acknowledgements}

This work was supported by the Instituto de Salud Carlos III grants \#PI07/0559, \#PI10/00316, and \#RD06/001/001 (RTA-RETICS), by the Spanish Ministry of Science and Technology (Consolider-C, \#SAF2007-64062), the Catalan Government (SGR2009-00731), and by the Catalan Institution for Research and Advanced Studies (ICREA Academia program). A Plaza-Zabala is a recipient of a predoctoral fellowship from the Spanish Ministry of Education.

\section{Conflict of interest}

The authors declare that they have no conflict of interest. 


\section{References}

1. de Lecea L, Kilduff TS, Peyron C, Gao X, Foye PE, Danielson PE, Fukuhara C, Battenberg EL, Gautvik VT, Bartlett FS 2nd, Frankel WN, van den Pol AN, Bloom FE, Gautvik KM, Sutcliffe JG (1998) The hypocretins: hypothalamus-specific peptides with neuroexcitatory activity. Proc Natl Acad Sci U S A 95:322-327

2. Sakurai T, Amemiya A, Ishii M, Matsuzaki I, Chemelli RM, Tanaka H, Williams SC, Richardson JA, Kozlowski GP, Wilson S, Arch JR, Buckingham RE, Haynes AC, Carr SA, Annan RS, McNulty DE, Liu WS, Terrett JA, Elshourbagy NA, Bergsma DJ, Yanagisawa M (1998) Orexins and orexin receptors: a family of hypothalamic neuropeptides and $\mathrm{G}$ protein-coupled receptors that regulate feeding behavior. Cell 20:573-585

3. Heinonen MV, Purhonen AK, Mäkelä KA, Herzig KH (2008) Functions of orexins in peripheral tissues. Acta Physiol (Oxf) 192:471-485

4. Alvarez CE, Sutcliffe JG (2002) Hypocretin is an early member of the incretin gene family. Neurosci Lett 324:169-172

5. Wong KK, Ng SY, Lee LT, Ng HK, Chow BK (2011) Orexins and their receptors from fish to mammals: a comparative approach. Gen Comp Endocrinol 171:124-130

6. Kukkonen JP, Holmqvist T, Ammoun S, Akerman KE (2002) Functions of the orexinergic/hypocretinergic system. Am J Physiol Cell Physiol 283:C1567-1591

7. Smart D, Sabido-David C, Brough SJ, Jewitt F, Johns A, Porter RA, Jerman JC (2001) SB-334867-A: the first selective orexin-1 receptor antagonist. $\mathrm{Br} \mathrm{J}$ Pharmacol 132:1179-1182

8. Ammoun S, Holmqvist T, Shariatmadari R, Oonk HB, Detheux M, Parmentier M, Akerman KE, Kukkonen JP (2003) Distinct recognition of OX1 and OX2 receptors by orexin peptides. J Pharmacol Exp Ther 305:507-514 
9. Takai T, Takaya T, Nakano M, Akutsu H, Nakagawa A, Aimoto S, Nagai K, Ikegami T (2006) Orexin-A is composed of a highly conserved C-terminal and a specific, hydrophilic N-terminal region, revealing the structural basis of specific recognition by the orexin-1 receptor. J Pept Sci 12:443-454

10. van den Pol AN, Gao XB, Obrietan K, Kilduff TS, Belousov AB (1998) Presynaptic and postsynaptic actions and modulation of neuroendocrine neurons by a new hypothalamic peptide, hypocretin/orexin. J Neurosci 18:7962-7971

11. Uramura K, Funahashi H, Muroya S, Shioda S, Takigawa M, Yada T (2001) Orexin-a activates phospholipase $\mathrm{C}$ - and protein kinase $\mathrm{C}$-mediated $\mathrm{Ca} 2+$ signaling in dopamine neurons of the ventral tegmental area. Neuroreport 12:1885-1889

12. Kohlmeier KA, Inoue T, Leonard CS (2004) Hypocretin/orexin peptide signaling in the ascending arousal system: elevation of intracellular calcium in the mouse dorsal raphe and laterodorsal tegmentum. J Neurophysiol 92:221-235

13. Narita M, Nagumo Y, Miyatake M, Ikegami D, Kurahashi K, Suzuki T (2007) Implication of protein kinase $\mathrm{C}$ in the orexin-induced elevation of extracellular dopamine levels and its rewarding effect. Eur J Neurosci 25:1537-1545

14. Xia JX, Fan SY, Yan J, Chen F, Li Y, Yu ZP, Hu ZA (2009) Orexin A-induced extracellular calcium influx in prefrontal cortex neurons involves L-type calcium channels. J Physiol Biochem 65:125-136

15. Gatfield J, Brisbare-Roch C, Jenck F, Boss C (2010) Orexin receptor antagonists: a new concept in CNS disorders? ChemMedChem 5:1197-1214

16. Woldan-Tambor A, Biegańska K, Wiktorowska-Owczarek A, Zawilska JB (2011) Activation of orexin/hypocretin type 1 receptors stimulates cAMP synthesis in primary cultures of rat astrocytes. Pharmacol Rep 63:717-723 
17. Li Y, Gao XB, Sakurai T, van den Pol AN (2002) Hypocretin/Orexin excites hypocretin neurons via a local glutamate neuron-A potential mechanism for orchestrating the hypothalamic arousal system. Neuron 36:1169-1181

18. Schlicker E, Kathmann M (2008) Presynaptic neuropeptide receptors. Handb Exp Pharmacol (184):409-434

19. Martin G, Fabre V, Siggins GR, de Lecea L (2002) Interaction of the hypocretins with neurotransmitters in the nucleus accumbens. Regul Pept 104:111-117

20. Davis SF, Williams KW, Xu W, Glatzer NR, Smith BN (2003) Selective enhancement of synaptic inhibition by hypocretin (orexin) in rat vagal motor neurons: implications for autonomic regulation. J Neurosci 23:3844-3854

21. Ma X, Zubcevic L, Brüning JC, Ashcroft FM, Burdakov D (2007) Electrical inhibition of identified anorexigenic POMC neurons by orexin/hypocretin. J Neurosci 14:1529-1533

22. Mori K, Kim J, Sasaki K (2011) Electrophysiological effects of orexin-B and dopamine on rat nucleus accumbens shell neurons in vitro. Peptides 32:246-252

23. Urbańska A, Sokołowska P, Woldan-Tambor A, Biegańska K, Brix B, Jöhren O, Namiecińska M, Zawilska JB (2011) Orexins/Hypocretins Acting at G(i) ProteinCoupled OX (2) Receptors Inhibit Cyclic AMP Synthesis in the Primary Neuronal Cultures. J Mol Neurosci doi:10.1007/s12031-011-9526-2

24. Peyron C, Tighe DK, van den Pol AN, de Lecea L, Heller HC, Sutcliffe JG, Kilduff TS (1998) Neurons containing hypocretin (orexin) project to multiple neuronal systems. J Neurosci 18:9996-10015

25. Baldo BA, Daniel RA, Berridge CW, Kelley AE (2003) Overlapping distributions of orexin/hypocretin- and dopamine-beta-hydroxylase immunoreactive fibers in rat brain regions mediating arousal, motivation, and stress. J Comp Neurol 464:220-237 
26. Marcus JN, Aschkenasi CJ, Lee CE, Chemelli RM, Saper CB, Yanagisawa M, Elmquist JK (2001) Differential expression of orexin receptors 1 and 2 in the rat brain. J Comp Neurol 435:6-25

27. Sakurai T, Mieda M (2011) Connectomics of orexin-producing neurons: interface of systems of emotion, energy homeostasis and arousal. Trends Pharmacol Sci 32: 451462

28. Kang JE, Lim MM, Bateman RJ, Lee JJ, Smyth LP, Cirrito JR, Fujiki N, Nishino S, Holtzman DM (2009) Amyloid-beta dynamics are regulated by orexin and the sleepwake cycle. Science 326:1005-1007

29. Johnson PL, Truitt W, Fitz SD, Minick PE, Dietrich A, Sanghani S, TräskmanBendz L, Goddard AW, Brundin L, Shekhar A (2010) A key role for orexin in panic anxiety. Nat Med 16:111-115

30. Sutcliffe JG, de Lecea L (2002) The hypocretins: setting the arousal threshold. Nat Rev Neurosci 3:339-349

31. Yamanaka A, Beuckmann CT, Willie JT, Hara J, Tsujino N, Mieda M, Tominaga M, Yagami K, Sugiyama F, Goto K, Yanagisawa M, Sakurai T (2003) Hypothalamic orexin neurons regulate arousal according to energy balance in mice. Neuron 38:701-713

32. Adamantidis AR, Zhang F, Aravanis AM, Deisseroth K, de Lecea L (2007) Neural substrates of awakening probed with optogenetic control of hypocretin neurons. Nature 450:420-424

33. Chemelli RM, Willie JT, Sinton CM, Elmquist JK, Scammell T, Lee C, Richardson JA, Williams SC, Xiong Y, Kisanuki Y, Fitch TE, Nakazato M, Hammer RE, Saper CB, Yanagisawa M (1999) Narcolepsy in orexin knockout mice: molecular genetics of sleep regulation Cell 98:437-451 
34. Willie JT, Chemelli RM, Sinton CM, Tokita S, Williams SC, Kisanuki YY, Marcus JN, Lee C, Elmquist JK, Kohlmeier KA, Leonard CS, Richardson JA, Hammer RE, Yanagisawa M (2003) Distinct narcolepsy syndromes in Orexin receptor-2 and Orexin null mice: molecular genetic dissection of Non-REM and REM sleep regulatory processes. Neuron 38:715-730

35. Lin L, Faraco J, Li R, Kadotani H, Rogers W, Lin X, Qiu X, de Jong PJ, Nishino S, Mignot E (1999) The sleep disorder canine narcolepsy is caused by a mutation in the hypocretin (orexin) receptor 2 gene. Cell 98:365-376

36. Nishino S, Ripley B, Overeem S, Lammers GJ, Mignot E (2000) Hypocretin (orexin) deficiency in human narcolepsy. Lancet 355:39-40

37. Thannickal TC, Moore RY, Nienhuis R, Ramanathan L, Gulyani S, Aldrich M, Cornford M, Siegel JM (2000) Reduced number of hypocretin neurons in human narcolepsy. Neuron 27:469-474

38. Brisbare-Roch C, Dingemanse J, Koberstein R, Hoever P, Aissaoui H, Flores S, Mueller C, Nayler O, van Gerven J, de Haas SL, Hess P, Qiu C, Buchmann S, Scherz M, Weller T, Fischli W, Clozel M, Jenck F (2007) Promotion of sleep by targeting the orexin system in rats, dogs and humans. Nat Med 13:150-155

39. Winsky-Sommerer R, Yamanaka A, Diano S, Borok E, Roberts AJ, Sakurai T, Kilduff TS, Horvath TL, de Lecea L (2004) Interaction between the corticotropinreleasing factor system and hypocretins (orexins): a novel circuit mediating stress response. J Neurosci 24:11439-11448

40. Winsky-Sommerer R, Boutrel B, de Lecea L (2005) Stress and arousal: the corticotrophin-releasing factor/hypocretin circuitry. Mol Neurobiol 32:285-294

41. Koob GF (2008) A role for brain stress systems in addiction. Neuron 59:11-34 
42. Boutrel B, Kenny PJ, Specio SE, Martin-Fardon R, Markou A, Koob GF, de Lecea L (2005) Role for hypocretin in mediating stress-induced reinstatement of cocaineseeking behavior. Proc Natl Acad Sci U S A 102:19168-19173

43. Hata T, Chen J, Ebihara K, Date Y, Ishida Y, Nakahara D (2011) Intra-ventral tegmental area or intracerebroventricular orexin-A increases the intra-cranial selfstimulation threshold via activation of the corticotropin-releasing factor system in rats. Eur J Neurosci 34:816-826

44. Macey DJ, Koob GF, Markou A (2000) CRF and urocortin decreased brain stimulation reward in the rat: reversal by a CRF receptor antagonist. Brain Res $866: 82-91$

45. Markou A, Koob GF (1991) Postcocaine anhedonia. An animal model of cocaine withdrawal. Neuropsychopharmacology 4:17-26

46. Epping-Jordan MP, Watkins SS, Koob GF, Markou A (1998) Dramatic decreases in brain reward function during nicotine withdrawal. Nature 393:76-79

47. Narita M, Nagumo Y, Hashimoto S, Narita M, Khotib J, Miyatake M, Sakurai T, Yanagisawa M, Nakamachi T, Shioda S, Suzuki T (2006) Direct involvement of orexinergic systems in the activation of the mesolimbic dopamine pathway and related behaviors induced by morphine. J Neurosci 26:398-405

48. España RA, Oleson EB, Locke JL, Brookshire BR, Roberts DC, Jones SR (2010) The hypocretin-orexin system regulates cocaine self-administration via actions on the mesolimbic dopamine system. Eur J Neurosci 31:336-348

49. Vittoz NM, Berridge CW (2006) Hypocretin/orexin selectively increases dopamine efflux within the prefrontal cortex: involvement of the ventral tegmental area. Neuropsychopharmacology 31:384-395 
50. Borgland SL, Taha SA, Sarti F, Fields HL, Bonci A (2006) Orexin A in the VTA is critical for the induction of synaptic plasticity and behavioral sensitization to cocaine. Neuron 49:589-601

51. O'Brien CP (1997) A range of research-based pharmacotherapies for addiction. Science 278: 66-70

52. Davis WM, Smith SG (1976) Role of conditioned reinforcers in the initiation, maintenance and extinction of drug seeking behavior. Pavlovian J Biol Sci 11: 222236

53. Shaham Y, Shalev U, Lu L, De Wit H, Stewart J (2003) The reinstatement model of drug relapse: history, methodology and major findings. Psychopharmacology (Berl) 168: $3-20$

54. Epstein DH, Preston KL, Stewart J, Shaham Y (2006) Toward a model of drug relapse: an assessment of the validity of the reinstatement procedure. Psychopharmacology (Berl) 189: 1-16

55. Bouton M, Swartzentruber D (1991) Sources of relapse after extinction in Pavlovian and instrumental learning. Clin Psychol Rev 11:18

56. Maldonado R, Berrendero F, Ozaita A, Robledo P (2011) Neurochemical basis of cannabis addiction. Neuroscience 181: 1-17

57. Seamans JK, Lapish CC, Durstewitz D (2008) Comparing prefrontal cortex of rats and primates: insights from electrophysiology. Neurotox Res 14:249-262

58. Berrendero F, Robledo P, Trigo JM, Martín-García E, Maldonado R (2010) Neurobiological mechanisms involved in nicotine dependence and reward: participation of the endogenous opioid system. Neurosci Biobehav Rev 35:220-231 
59.Trigo JM, Martín-García E, Berrendero F, Robledo P, Maldonado R (2010) The endogenous opioid system: a common substrate in drug addiction. Drug Alcohol Depend 108: 183-194

60. Sanchis-Segura C, Spanagel R (2006) Behavioural assessment of drug reinforcement and addictive features in rodents: an overview. Addict Biol 11: 2-38

61. Markou A, Weiss F, Gold LH, Caine SB, Schulteis G, Koob GF (1993) Animal models of drug craving. Pychopharmacology (Berl) 112: 163-182

62. Aguilar MA, Rodriguez-Arias M, Minarro J (2009) Neurobiological mechanisms of the reinstatement of drug-conditioned place preference. Brain Res Rev 59: 253-277

63. Childs E, de Wit H (2009) Amphetamine-induced place preference in humans. Biol Psychiatry 65: 900-904

64. Yahyyavi-Firouz-Abadi N, See RE (2009) Anti-relapse medications: preclinical models for drug addiction treatment. Pharmacol Ther 124: 235-247

65. Steketee JD, Kalivas PW (2011) Drug wanting: behavioral sensitization and relapse to drug-seeking behavior. Pharmacol Rev 63: 348-365

66. Soria G, Barbano MF, Maldonado R, Valverde O (2008) A reliable method to study cue-, priming-, and stress-induced reinstatement of cocaine self-administration in mice. Psychopharmacology (Berl) 199:593-603

67. Yan Y, Yamada K, Nitta A, Nabeshima T (2007) Transient drug-primed but persistent cue-induced reinstatement of extinguished methamphetamine-seeking behavior in mice. Behav Brain Res 177: 261-268

68. Trigo JM, Panayi F, Soria G, Maldonado R, Robledo P (2006) A reliable model of intravenous MDMA self-administration in naïve mice. Psychopharmacology (Berl) 184: $212-220$ 
69. Tsiang MT, Janak PH (2006) Alcohol seeking in C57BL/6 mice induced by conditioned cues and contexts in the extinctions-reinstatement model. Alcohol 38: $81-88$

70. Martín-García E, Barbano MF, Galeote L, Maldonado R (2008) New operant model of nicotine-seeking behavior in mice. Int J Neuropsychopharmacol 23: 343-356

71. Martín-García E, Burokas A, Kostrzewa E, Gieryk A, Korostynski M, Ziolkowska B, Przewlocka B, Przewlocki R, Maldonado R (2010) New operant model of reinstatement of food-seeking behavior in mice. Psychopharmacology (Berl) 215: $49-70$

72. Willner P (1984) The validity of animal models of depression. Psychopharmacology (Berl) 83:1-16

73. De Wit H (1996) Priming effects with drugs and other reinforces. Experimental and Clinical Psychopharmacology 4: 5-11

74. Carter BL, Tiffany ST (1999) Meta-analysis of cue-reactivity in addiction research. Addiction 94: 327-340

75. Shiffman S, Hickcox M, Paty JA, Gnys M, Kassel JD, Richards TJ (1996) Progression from a smoking lapse to relapse: prediction from abstinence violation effects, nicotine dependence, and lapse characteristics. J Consult Clin Psychol 64: 993-1002

76. Gerber GJ, Strech R (1975) Drug-induced reinstatement of extinguished selfadministration behavior in monkeys. Pharmacol Biochem Behav 3: 1055-1061

77. See RE (2002) Neural substrates of conditioned-cued relapse to drug-seeking behavior. Pharmacol Biochem Behav 71: 517-529 
78. Weiss F, Maldonado-Vlaar CS, Parsons LH, Kerr TM, Smith D1, Ben-Shahar O (2000) Control of cocaine-seeking behavior by drug-associated stimuli in rats: effects on recovery of extinguished operant-responding and extracellular dopamine levels in amygdale and nucleus accumbens. Proc Natl Acad Sci USA 97: 4321-4326

79. Fuchs RA, Evans KA, Ledford CC, Parker MP, Case JM, Mehta RH, See RE (2005) The role of the dorsomedial prefrontal cortex, basolateral amygdala, and dorsal hippocampus in contextual reinstatement of cocaine seeking in rats. Neuropsychopharmacology 30: 296-309

80. Sinha R, Catapano D, O’Malley S (1999) Stress-induced craving and stress response in cocaine dependent individuals. Psychopharmacology (Berl) 142: 343-351

81. Piazza PV, Le Moal M (1998) The role of stress in drug self-administration. Trends Pharmacol Sci 19:67-74

82. Lee B, Tiefenbacher S, Platt DM, Spealman RD (2004) Pharmacological blockade of alpha2-adrenoceptors induces reinstatement of cocaine-seeking behavior in squirrel monkeys. Neuropsychopharmacology 29: 686-693

83. Shepard JD, Bossert M, Liu Sy, Shaham Y (2004) The anxiogenic drug yohimbine reinstates methamphetamine seeking in rat model of drug relapse. Biol Psychiatry 55: 1082-1089

84. McPherson CS, Featherby T, Krstew E, Lawrence AJ (2007) Quantification of phosphorylated cAMP-response element-binding protein expression throughout the brain of amphetamine-sensitized rats: activation of hypothalamic orexin Acontaining neurons. J Pharmacol Exp Ther 323:805-812

85. Morshedi MM, Meredith GE (2008) Repeated amphetamine administration induces Fos in prefrontal cortical neurons that project to the lateral hypothalamus but not the 
nucleus accumbens or basolateral amygdala. Psychopharmacology (Berl) 197:179189

86. Quarta D, Valerio E, Hutcheson DM, Hedou G, Heidbreder C (2010) The orexin-1 receptor antagonist SB-334867 reduces amphetamine-evoked dopamine outflow in the shell of the nucleus accumbens and decreases the expression of amphetamine sensitization. Neurochem Int 56:11-15

87. Harris GC, Wimmer M, Aston-Jones G (2005) A role for lateral hypothalamic orexin neurons in reward seeking. Nature 437:556-559

88. Sharf R, Guarnieri DJ, Taylor JR, DiLeone RJ (2010) Orexin mediates morphine place preference, but not morphine-induced hyperactivity or sensitization. Brain Res $1317: 24-32$

89. España RA, Melchior JR, Roberts DC, Jones SR (2011) Hypocretin 1/orexin A in the ventral tegmental area enhances dopamine responses to cocaine and promotes cocaine self-administration. Psychopharmacology (Berl) 214:415-426

90. Smith RJ, See RE, Aston-Jones G (2009) Orexin/hypocretin signaling at the orexin 1 receptor regulates cue-elicited cocaine-seeking. Eur J Neurosci 30:493-503

91. Borgland SL, Chang SJ, Bowers MS, Thompson JL, Vittoz N, Floresco SB, Chou J, Chen BT, Bonci A (2009) Orexin A/hypocretin-1 selectively promotes motivation for positive reinforcers. J Neurosci 29:11215-11225

92. Wang B, You ZB, Wise RA (2009) Reinstatement of cocaine seeking by hypocretin (orexin) in the ventral tegmental area: independence from the local corticotropinreleasing factor network. Biol Psychiatry 65:857-862 
93. Smith RJ, Tahsili-Fahadan P, Aston-Jones G (2010) Orexin/hypocretin is necessary for context-driven cocaine-seeking. Neuropharmacology 58:179-184

94. Aston-Jones G, Smith RJ, Sartor GC, Moorman DE, Massi L, Tahsili-Fahadan P, Richardson KA (2010) Lateral hypothalamic orexin/hypocretin neurons: A role in reward-seeking and addiction. Brain Res 1314:74-90

95. James MH, Charnley JL, Levi EM, Jones E, Yeoh JW, Smith DW, Dayas CV (2011) Orexin-1 receptor signalling within the ventral tegmental area, but not the paraventricular thalamus, is critical to regulating cue-induced reinstatement of cocaine-seeking. Int J Neuropsychopharmacol 14:684-690

96. Stuber GD, Klanker M, de Ridder B, Bowers MS, Joosten RN, Feenstra MG, Bonci A (2008) Reward-predictive cues enhance excitatory synaptic strength onto midbrain dopamine neurons. Science 321:1690-1692

97. Harris GC, Wimmer M, Randall-Thompson JF, Aston-Jones G (2007) Lateral hypothalamic orexin neurons are critically involved in learning to associate an environment with morphine reward. Behav Brain Res 183:43-51

98. Georgescu D, Zachariou V, Barrot M, Mieda M, Willie JT, Eisch AJ, Yanagisawa M, Nestler EJ, DiLeone RJ (2003) Involvement of the lateral hypothalamic peptide orexin in morphine dependence and withdrawal. J Neurosci 23:3106-3111

99. Sharf R, Sarhan M, Dileone RJ (2008) Orexin mediates the expression of precipitated morphine withdrawal and concurrent activation of the nucleus accumbens shell. Biol Psychiatry 64:175-183

100.Azizi H, Mirnajafi-Zadeh J, Rohampour K, Semnanian S (2010) Antagonism of orexin type 1 receptors in the locus coeruleus attenuates signs of naloxoneprecipitated morphine withdrawal in rats. Neurosci Lett 482:255-259 
101.Zhou Y, Bendor J, Hofmann L, Randesi M, Ho A, Kreek MJ (2006) Mu opioid receptor and orexin/hypocretin mRNA levels in the lateral hypothalamus and striatum are enhanced by morphine withdrawal. J Endocrinol 191:137-145

102.Markou A (2008) Review. Neurobiology of nicotine dependence. Philos Trans R Soc Lond B Biol Sci 363:3159-3168

103.Kenny PJ (2011) Tobacco dependence, the insular cortex and the hypocretin connection. Pharmacol Biochem Behav 97:700-707

104.Pasumarthi RK, Reznikov LR, Fadel J (2006) Activation of orexin neurons by acute nicotine. Eur J Pharmacol 535:172-176

105.Plaza-Zabala A, Martín-García E, de Lecea L, Maldonado R, Berrendero F (2010) Hypocretins regulate the anxiogenic-like effects of nicotine and induce reinstatement of nicotine-seeking behavior. J Neurosci 30:2300-2310

106.Plaza-Zabala A, Flores A, Maldonado R, Berrendero F (2012) Hypocretin/Orexin signaling in the hypothalamic paraventricular nucleus is essential for the expression of nicotine withdrawal. Biol Psychiatry 71:214-223

107.LeSage MG, Perry JL, Kotz CM, Shelley D, Corrigall WA (2010) Nicotine selfadministration in the rat: effects of hypocretin antagonists and changes in hypocretin mRNA. Psychopharmacology (Berl) 209:203-212

108.Kane JK, Parker SL, Matta SG, Fu Y, Sharp BM, Li MD (2000) Nicotine upregulates expression of orexin and its receptors in rat brain. Endocrinology $141: 3623-3629$

109.Hollander JA, Lu Q, Cameron MD, Kamenecka TM, Kenny PJ (2008) Insular hypocretin transmission regulates nicotine reward. Proc Natl Acad Sci U S A 105:19480-19485 
110.Naqvi NH, Rudrauf D, Damasio H, Bechara A (2007) Damage to the insula disrupts addiction to cigarette smoking. Science 315:531-534

111.von der Goltz C, Koopmann A, Dinter C, Richter A, Rockenbach C, Grosshans M, Nakovics H, Wiedemann K, Mann K, Winterer G, Kiefer F (2010) Orexin and leptin are associated with nicotine craving: a link between smoking, appetite and reward. Psychoneuroendocrinology 35:570-577

112.Lambe EK, Olausson P, Horst NK, Taylor JR, Aghajanian GK (2005) Hypocretin and nicotine excite the same thalamocortical synapses in prefrontal cortex: correlation with improved attention in rat. J Neurosci 25:5225-5229

113.Pasumarthi RK, Fadel J (2008) Activation of orexin/hypocretin projections to basal forebrain and paraventricular thalamus by acute nicotine. Brain Res Bull 77:367-373

114.Lawrence AJ (2010) Regulation of alcohol-seeking by orexin (hypocretin) neurons. Brain Res 1314:124-129

115.Lawrence AJ, Cowen MS, Yang HJ, Chen F, Oldfield B (2006) The orexin system regulates alcohol-seeking in rats. Br J Pharmacol 148: 752-759

116.Richards JK, Simms JA, Steensland P, Taha SA, Borgland SL, Bonci A, Bartlett SE (2008) Inhibition of orexin-1/hypocretin-1 receptors inhibits yohimbine-induced reinstatement of ethanol and sucrose seeking in Long-Evans rats. Psychopharmacology (Berl) 199: 109-117

117.Moorman DE, Aston-Jones G (2009) Orexin-1 receptor antagonism decreases ethanol consumption and preference selectively in high-ethanol--preferring SpragueDawley rats. Alcohol 43: 379-386

118.Jupp B, Krivdic B, Krstew E, Lawrence AJ (2011) The orexin-1 receptor antagonist SB-334867 dissociates the motivational properties of alcohol and sucrose in rats. Brain Res 1391: 54-59 
119.Schneider ER, Rada P, Darby RD, Leibowitz SF, Hoebel BG (2007) Orexigenic peptides and alcohol intake: differential effects of orexin, galanin, and ghrelin. Alcohol Clin Exp Res 31: 1858-1865

120.Morganstern I, Chang GQ, Barson JR, Ye Z, Karatayev O, Leibowitz SF (2010) Differential effects of acute and chronic ethanol exposure on orexin expression in the perifornical lateral hypothalamus. Alcohol Clin Exp Res 34: 886-896

121.Shoblock JR, Welty N, Aluisio L, Fraser I, Motley ST, Morton K, Palmer J, Bonaventure P, Carruthers NI, Lovenberg TW, Boggs J, Galici R (2011) Selective blockade of the orexin-2 receptor attenuates ethanol self-administration, place preference, and reinstatement. Psychopharmacology (Berl) 215: 191-203

122.Voorhees CM, Cunningham CL (2011) Involvement of the orexin/hypocretin system in ethanol conditioned place preference. Psychopharmacology (Berl) 214: 805-818

123.Jupp B, Krstew E, Dezsi G, Lawrence AJ (2011) Discrete cue-conditioned alcoholseeking after protracted abstinence: pattern of neural activation and involvement of orexin-1 receptors. Br J Pharmacol 162: 880-889

124.Hamlin AS, Newby J, McNally GP (2007) The neural correlates and role of D1 dopamine receptors in renewal of extinguished alcohol-seeking. Neuroscience 146: 525-536

125.Dayas CV, McGranahan TM, Martin-Fardon R, Weiss F (2008) Stimuli linked to ethanol availability activate hypothalamic CART and orexin neurons in a reinstatement model of relapse. Biol Psychiatry 63: 152-157

126.Xu YL, Reinscheid RK, Huitron-Resendiz S, Clark SD, Wang Z, Lin SH, Brucher FA, Zeng J, Ly NK, Henriksen SJ, de Lecea L, Civelli O (2004) Neuropeptide S: a neuropeptide promoting arousal and anxiolytic-like effects. Neuron 43: 487-497 
127.Cannella N, Economidou D, Kallupi M, Stopponi S, Heilig M, Massi M, Ciccocioppo R (2009) Persistent increase of alcohol-seeking evoked by neuropeptide S: an effect mediated by the hypothalamic hypocretin system. Neuropsychopharmacology 34: 2125-2134

128.von der Goltz C, Koopmann A, Dinter C, Richter A, Grosshans M, Fink T, Wiedemann K, Kiefer F (2011) Involvement of orexin in the regulation of stress, depression and reward in alcohol dependence. Horm Behav 60: 644-650

129.Bayerlein K, Kraus T, Leinonen I, Pilniok D, Rotter A, Hofner B, Schwitulla J, Sperling W, Kornhuber J, Biermann T (2011) Orexin A expression and promoter methylation in patients with alcohol dependence comparing acute and protracted withdrawal. Alcohol 45: 541-547

130.Aston-Jones G, Smith RJ, Moorman DE, Richardson KA (2009) Role of lateral hypothalamic orexin neurons in reward processing and addiction. Neuropharmacology 56: 112-121

131.Harris GC, Aston-Jones G (2006) Arousal and reward: a dichotomy in orexin function. Trends Neurosci 29:571-577

132.Sun W (2011) Dopamine Neurons in the Ventral Tegmental Area: Drug-induced Synaptic Plasticity and Its Role in Relapse to Drug-seeking Behavior. Curr Drug Abuse Rev 2011 Aug 12. [Epub ahead of print]

133.Korotkova TM, Sergeeva OA, Eriksson KS, Haas HL, Brown RE (2003) Excitation of ventral tegmental area dopaminergic and nondopaminergic neurons by orexins/hypocretins. J Neurosci 23:7-11

134.Fadel J, Deutch AY (2002) Anatomical substrates of orexin-dopamine interactions: lateral hypothalamic projections to the ventral tegmental area. Neuroscience $111: 379-387$ 
135.Balcita-Pedicino JJ, Sesack SR (2007) Orexin axons in the rat ventral tegmental area synapse infrequently onto dopamine and gamma-aminobutyric acid neurons. $\mathbf{J}$ Comp Neurol 503:668-684

136.Scammell TE, Winrow CJ (2011) Orexin receptors: pharmacology and therapeutic opportunities. Annu Rev Pharmacol Toxicol 51: 243-266

137.Huang H, Acuna-Goycolea C, Li Y, Cheng HM, Obrietan K, van den Pol AN (2007) Cannabinoids excite hypothalamic melanin-concentrating hormone but inhibit hypocretin/orexin neurons: implications for cannabinoid actions on food intake and cognitive arousal. J Neurosci 27:4870-4881

138.Crespo I, Gómez de Heras R, Rodríguez de Fonseca F, Navarro M (2008) Pretreatment with subeffective doses of Rimonabant attenuates orexigenic actions of orexin A-hypocretin 1. Neuropharmacology 54:219-225

139.Ho YC, Lee HJ, Tung LW, Liao YY, Fu SY, Teng SF, Liao HT, Mackie K, Chiou LC (2011) Activation of orexin 1 receptors in the periaqueductal gray of male rats leads to antinociception via retrograde endocannabinoid (2-arachidonoylglycerol)induced disinhibition. J Neurosci 31:14600-14610 


\section{Figure legends}

Fig. 1. Schematic representation of the hypocretin system. Neurons expressing hypocretin (dots) project widely throughout the brain modulating diverse physiological functions. PFC, prefrontal cortex; NAc, nucleus accumbens; BNST, bed nucleus of the stria terminalis; VTA, ventral tegmental area; LH, lateral hypothalamus.

Fig. 2. Diagram showing the potential therapeutic utility of hypocretin receptor antagonists on different stages of drug addiction. Hcrtr-1, hypocretin receptor-1; Hcrtr2 , hypocretin receptor- 2 . 